\title{
Developmental Levels in Adult's Conceptions of Health and Disease ${ }^{1}$
}

\author{
Joaquim C. Reis ${ }^{2}$ \\ Universidade de Coimbra \\ Fernando S. Fradique \\ Universidade de Lisboa
}

\begin{abstract}
A socio-cognitive developmental perspective suggests that conceptions regarding health and disease processes may present different levels of openness, flexibility, inclusiveness and differentiation, and thus can be ordered into different levels. We present a qualitative study on lay significations regarding health and disease processes, endorsed by 67 adults. The results show that these adults have different socio-cognitive developmental competences related to health and disease processes. For each dimension of significations of health and disease, it is possible to sequence lay person's conceptions developmentally. Each level is distinct qualitatively, including responses characterized by a higher degree of differentiation, integration and complexity than the previous level. Finally, the implications of this approach to clinical and educational methods are discussed.
\end{abstract}

Keywords: adult's conceptions of health and disease; socio-cognitive development.

\section{Níveis de Desenvolvimento nas Concepções dos Adultos sobre Saúde e Doença}

\begin{abstract}
RESUMO - Na perspectiva do desenvolvimento sociocognitivo, as concepções de saúde e doença podem apresentar diferentes níveis de abertura, flexibilidade, inclusividade e diferenciação e podem ser ordenadas em diferentes níveis de desenvolvimento. O presente estudo incidiu sobre as significações leigas de saúde e doença de um grupo de 67 adultos. Os resultados indicam que esses adultos se situam em diferentes níveis nas suas competências de desenvolvimento sociocognitivo relacionadas com os processos de saúde e doença, tendo sido possível sequenciar as suas significações em níveis distintos. Cada nível é distinto qualitativamente, incluindo respostas caracterizadas por uma maior diferenciação, integração e complexidade em relação ao nível precedente. As implicações dessa abordagem para os métodos clínicos e educativos são discutidas.
\end{abstract}

Palavras-chave: concepções de saúde e doença em adultos; desenvolvimento sociocognitivo.

Cognitive-developmental studies suggest that children's conceptions $^{3}$ of illness evolve in a systematic and predictable sequence consistent with Piaget's theory of cognitive development (e.g., Bibace \& Walsh, 1979; Bibace, Schmidt \& Walsh, 1994; Burbach \& Peterson, 1986; Perrin \& Gerrity, 1981). For example, Bibace and Walsh (1979) proposed a sequence of six levels of conceptions regarding definition, causes and treatment of diseases in children and adolescents. According to those authors, the reasoning characteristic of each level is general in nature and indeed they provide the explanations for a wide range of illnesses (Bibace \& cols. 1994).

The available data reviewed by Burbach and Peterson (1986) indicate a relationship between chronological age/ cognitive maturity and level of complexity of children's illness concepts. For instance, older and more cognitively mature children conceptualized illness in terms of specific symptoms and diseases, and apprehended the psychological,

1 The study, as part of a larger project (Socio-cognitive development of subjective representations regarding health and disease: implications for the health education), has been funded by Fundação para a Ciência e Tecnologia, Lisboa, Portugal (PRAXIS/ PCSH/C/PSI/89/96) and coordinated by J. Reis, University of Coimbra, Portugal. Thanks to João Silvestre, a cognitive-behavior therapist in private practice in Manhattan, New York City, for his helpful comments and suggestions.

2 Correspondence address: Rua do Colégio Novo. Coimbra, Portugal, 3001-802.E-mail: joaquimreis@netcabo.pt.

3 In this paper, conceptions and significations are utilized as synonymous. affective and social aspects of physical illness. In turn, younger and less cognitively mature children conceptualized illness in global and non-specific ways and did not comprehend the psychosocial aspects of disease. It is interesting to note that the consideration of a psychological dimension corresponds to a higher level of conceptual development in children and adolescents. In fact, if we do a parallel with scientific models, we can say that the main assertions of the psychosomatic model of disease correspond to the more developed level of children and adolescents. Furthermore, children and adolescents were not able to express conceptions of wholeness or integration of the human being, included in a holistic and dialectical model (Basseches, 1984). It seems that those conceptions are characteristic of adult thinking. Empirical findings about the development of mind-body concepts (Broughton, 1980) indicate that the last three developmental stages are not shown before the third decade of life. In "dialectical stage", the higher level, nature and culture are seen as penetrating each other.

Empirical studies focusing on the development of concepts of physical illness have been restricted to children and adolescents. There are many studies in the field of health psychology that focus on adults' concepts related to physical illness, but they are not integrated into a developmental framework (e.g., Cameron \& Leventhal, 2003; Cohen \& Lazarus, 1979; Coyne \& Holroyd, 1982; Leventhal, Nerenz \& Steele, 1984; Rosenstock, 1966; Skelton \& Croyle, 1991; 
Turk \& Meichenbaum, 1991). Some research studies confirm that adults operate at varying levels. In a study with adult cardiac surgery inpatients (Reis, 1992), it was found that these patients were functioning at different levels of significations regarding their disease and their emotional symptoms, ranging from lower to higher levels. In the same study, it was also found that when patients that were functioning at lower levels were exposed to conceptions typical of higher levels, some of them could not understand these conceptions. In the domain of the development of reflective thinking, King and Kitchener (1994) showed that individuals ranging from 16 to 34 years of age were functioning at different levels of conceptions regarding epistemological thinking. Summarizing the results from a number of research studies, Kegan (1994) asserts that only a small percentage of adults ever reach the higher level and that this never occurs before the age of 40. Moreover, this author says that most adults are "in over their heads", that is, in their work or in other contexts, they are frequently being asked to perform at levels beyond their current functioning.

Joyce-Moniz and Reis (1991) and Reis (1998), in their work based on the Piagetian constructivist framework, propose a developmental characterization of adult conceptions regarding health and disease processes. Each successive level represents a more complex form of justification regarding disease, providing more inclusive and better-integrated assumptions. All these sequences of conceptions are theoretical in the sense that they were elaborated according to the cross-sectional convergences of developmental sequences of significations of cognitive-developmental theory (Joyce-Moniz, 1989, 1993). In general, the explanations regarding health and disease evolve from an atomistic, one-dimensional and physical conception of disease towards a multidimensional conception that includes the psychological, physical and social aspects of disease (higher levels). Table 1 illustrates this developmental progression that serves as criteria to analyze significations. This developmental progression of significations regarding health and disease is formally parallel to the general model of progressive differentiation and integration of cognitivedevelopmental theory (e.g., Piaget, 1970; Kohlberg, 1969; Loevinger, 1966; Selman, 1980).

The aim of the present study was threefold (for a wider pool of objectives, cf. Reis \& Fradique, 2000, 2002): (1) to assess significations regarding health (e.g., what it means to you to be healthy) and disease (e.g., what it means to you to be ill) held by adult lay persons; (2) to verify if those significations can be ordered developmentally from least to most mature; and (3) to propose developmental sequences of significations regarding health and disease.

\section{Method}

\section{Participants}

Ethical approval was obtained for the study. Interviewees gave permission for qualitative interviews to be tape-recorded and the data to be published anonymously. Sixty seven adult participants (over 18 years old) were randomly drawn from the universe of lay persons (e.g., persons that are not health specialists or professionals) living in the region of Lisbon, Portugal. There were 29 male and 38 female in the sample. Because we were interested in the adult life span, we sampled from young adulthood $(\mathrm{n}=27)$, middle-aged $(\mathrm{n}=24)$ and laterlife $(\mathrm{n}=16)$. Age minimum was 19 years old and maximum, 91 years old. On average, participants were 41 years old, and had 10.6 years of school education (minimum $=4$ and maximum=17).

\section{Procedure}

To assess participant's conceptions regarding health and disease, an individual semi-structured interview based upon the Piagetian "clinical method" was used (Piaget, 1926; Reis, 1994). This method allows eliciting the reasoning processes of the individual. The subject is required to justify each of their initial answers (e.g., why do you think that way? Can you explain it better?).

Data was collected through the "Cognitive-Developmental Interview Protocol on Health and Disease" (Reis \& Fradique, 2000). This protocol was developed in order to address four different concepts regarding health and disease processes (e.g., causality, disease, health and prevention). Four short narratives $\left(\mathrm{N} 1 / \mathrm{N} 2, \mathrm{~N} 3, \mathrm{~N} 4\right.$ and $\left.\mathrm{N}^{4}\right)$ were elaborated for each of the concepts considered. Each of the narratives is representative of a given socio-cognitive developmental level. An example of a health narrative representative of Level 4 follows:

Being healthy means that we can comply with our personal, familiar and professional duties and obligations. All our bodily organs work as well as our mind and we feel in good shape. We are in good tune with our social environment and with ourselves. Our social life is in equilibrium; we have good relationships with other people, namely our family, our friends, our colleagues. We must think reasonably about our life and ourselves, and conduct a good and healthy lifestyle. We must listen to what the experts say and avoid the bad habits ... we must be responsible towards our life, and make informed choices ... responsible attitudes and behaviors are a good investment in health".

Narratives were elaborated on the basis of a sociocognitive synthesis of several authors in Developmental Psychology (Joyce-Moniz, 1993) and on the basis of a sequencing of significations regarding health and disease processes (Joyce-Moniz \& Reis, 1991; Reis, 1998). As it was mentioned before, in this paper only disease and health conceptions will be addressed.

Each person was interviewed individually. The Interview Protocol was used as follows. First, before being exposed to each one of the four narratives, for each dimension, the interviewed person was asked to speak spontaneously regarding that dimension (What does it means to you to be healthy? What does health

4 We create only one narrative for representing levels 1 and 2 (n1/n2) because we had some difficulties in distinguish clearly these two levels with a short narrative. 
means to you?). This allowed us to assess the personal significations regarding a given dimension before the person was exposed to, and influenced by the narratives. Second, the interviewed person was exposed to each of the narratives, for each dimension, and confronted with several questions: (a) Do you agree with what this person just said?; (b) What do you disagree with?; (c) What do you agree with?. These probes are used to elicit the subject's reasoning. The subject was invited to speak freely and openly and to justify his/her own opinions. The justifications that were solicited following the expression of agreement or disagreement concerning a given narrative made it possible to evaluate the degree to which the person was developmentally competent to hold the significations included in the narratives. Finally, the interviews' concepts were presented in the following order: (a) causality; (b) disease; (c) health; and (d) prevention. It would have been better to follow a randomised sequencing of concepts in order to dilute eventual systematic learning effects, but that was not a concern at the time. Interviews required about 60 minutes each.

All the interviews were audio taped and transcribed. For each of the interviews a content analysis was performed based on the developmental criteria defined in Table 1. A doctorallevel psychologist rated all 67 interviews in accordance with cognitive-developmental criteria. Before, to establish the reliability of the developmental categories of significations, this psychologist and a second doctoral-level psychologist rated a random sample of one quarter of the interviews and crosschecked their criteria. Inter-rater agreement on developmental categories was $92 \%$.

\section{Results}

\section{Analysis of disease significations}

Significations regarding disease (i.e., what it means to you to be ill) could be organized in terms of 14 categories along four dimensions: biological, psychological/emotional, social and biopsychosocial relationships. Following the definition of each category we illustrate it with a typical signification.

\section{Biological dimension (B)}

B1. Modification of function and/or structure of the body. The definition of disease is centered on the physical dimension: function and/or structure modification of the body. Body is conceived as similar to a machine: "When something is malfunctioning the machine does not work $100 \% \ldots$ in this case, the pieces are the organs and if they are not working as they should, then it is because something is broken ... I am ill when my organs do not work properly".

B2. Negative and dichotomized global state. Disease is defined from a negative and dichotomized global state point of view: "To be ill is feeling bad, it is when something is in me and I do not feel good with".

B3. Lack of health. Disease is defined from a symmetric and dichotomized perspective - disease is lack of health:
"Disease is, in the first place, lack of health, and can be checked out in several different ways".

\section{Psychological dimension $(P)$}

P1. Subjectivity is integrated in the disease process. What is or is not a disease depends in some way on the interpretation that people do: each person has a different way of looking at a disease, the disease even depends on the society or social group of belonging: "if one feels good with him/herself, if one lives his/her normal life, I think there is no problem at all. But if a person thinks that he/ she is fat, for example, and sees that as a problem, one can, then, say that he/she is ill just because he/she considers $\mathrm{him} /$ herself that way... to be ill depends on ourselves, depends on the degree of importance that we attribute to the fact that we may be ill ... there is a medical severity, or in other words, a scientific severity of the diseases. And after that, there is a degree of severity that each one attributes to his/her illness ... the kind of approach he/ she has to diseases".

\section{Social dimension $(S)$}

S1. Not taking profit from life. The disease is an obstacle to personal gains, wishes, interests and opportunities maximization, and weakens functional capacities: "When the person is ill, he/she does not take as much profit from life as when he/she is healthy ... sometimes, against our will, we are ill, we try to reach certain objectives, but the disease is really an obstacle to that".

S2. Functional body. The disease is defined mainly from what the person can or cannot do: "I am ill when I cannot work, or I cannot do my normal life".

S3. Centering on significant others. Centering on relational problems due to the disease or on the consequences upon significant others: "When you are ill it is not only you that stays worried. There always a mother or a father, or someone else that is with you and that is also worried and this is awful to see our familiars and friends worried".

S4. Lack of the capacity to perform according to social responsibilities. Centering on social role and function disorders and on failures to fulfill social responsibilities: "If we are not in the mood to appreciate or to enjoy different things, or if we are not able to complete ... well ... to serve our society, we do not feel complete and that will be ... we feel down and this is one reason to feel even worse".

S5. Centering on authority (physician) significations: Conception of disease is centered on an unconditional adherence to medical significations: "Right now I am ill because I went to the doctor and I know I am ill”.

\section{Biopsychosocial relationships (BR)}

BR1. Introduction of the psychological dimension, but defined in a global sense. The disease includes the psychological dimension but its relation with the physical dimension is still vague and uncertain: "Of course psychological aspects are ... fundamental in what concerns the disease. When we are psychologically fine, we get something positive from things ... it help us to feel better". 
Table 1. Developmental criteria for health and disease concepts.

\section{Biological dimension}

\begin{tabular}{cl}
\hline 1 & Global bodily sensation dichotomized (e.g., feel bad or feel good); body interested focused on somatic sensations. \\
\hline 2 & $\begin{array}{l}\text { Somatic differentiation: compared to the previous level, somatic perception is differentiated, including a } \\
\text { quantitative and a qualitative evaluation of multiple symptoms; body interest focused on specific skills to control } \\
\text { environment and others. }\end{array}$ \\
\hline 3 & $\begin{array}{l}\text { Identical to the previous level but body interest is focused on global functioning of the most well-known organs } \\
\text { (e.g., liver, heart). }\end{array}$ \\
\hline 5 & $\begin{array}{l}\text { Body is conceived as an organization composed both as organs with internal physiological functions and bodily systems } \\
\text { (e.g., cardiovascular, digestive) that connect the organs. Body interest focused on the functioning of bodily systems. }\end{array}$ \\
\hline 5 & $\begin{array}{l}\text { Body as an integral part of the mind and vice-versa; body interest focused on the organic systems but with an } \\
\text { emphasis on psychological transformations (e.g., loss or gain of mental capacities). }\end{array}$ \\
\hline
\end{tabular}

\section{Psychological dimension}

1 Undifferentiated; psychological/emotional experiences are identical to body sensations; objective reality identical to what we see.

2 Psychological/emotional experiences are identical to hedonic states of pleasure and displeasure; objective reality exists but sometimes cannot be immediately known; absolute knowledge depends on a large accumulation of evidence.

3 Body mind differentiation; emotional experiences are differentiated and connected with subjective meanings; emotion becomes a psychological as well a somatic experience, but is a one-dimensional experience.

4 Body-mind interaction; emotional experiences are associated with value systems and preferences; emotions are described in terms of complex and idiosyncratic feelings; the individual is able to describe complex and differentiated emotional states and captures his or her subjective experience; significations regarding health and disease processes are subjective in nature but can be rationally understood.

5 Body-mind integration; emotion described in terms (metacognitive) of quantity and quality; greater differentiation and integration in one's appreciation of the experience of others in the context of an ongoing differentiated awareness of one's experience. The experience of the body is based on subjective and idiosyncratic evaluations of the organism conceived as a biopsychological whole.

\section{Social/moral dimension}

\begin{tabular}{cl}
\hline 1 & Pre-social orientation: amorality and anomy. Centering on authority figures (of knowledge and power). \\
\hline 2 & Instrumental orientation; individual seeks to avoid the loss of opportunity. \\
\hline 3 & Pro-social orientation: relational conformism; individual seeks to avoid the loss of approval from significant others. \\
\hline 4 & Pro-social orientation: institutional conformism; individual seeks to avoid the loss of a social order. \\
\hline 5 & Post-conventional orientation: relativism and autonomy; individual seeks to avoid loss of autonomy. \\
\hline 1 & Biopsychosocial relationships \\
\hline 2 & $\begin{array}{l}\text { Body centering and body functionality; physical monism. } \\
\text { emerge but without interacting. }\end{array}$ \\
\hline 3 & Causal sequence of factors (biological, psychological and social) with biological focus. \\
\hline 4 & Biological, psychological and social interaction - with biological focus. \\
\hline 5 & Biopsychosocial integration (holism). Body and mind construct each other. \\
\hline
\end{tabular}


BR2. Psychosomatic relationships. The psychological dimension, defined in a global way, has an influence over the physical component of the disease, but when compared with the previous conception, the physical dimension's influence over the psychological one is added: "I think that the mindstate is related to the physical and the psychological aspects ... they are eminently connected ... if the body is feeling bad the head is not well. Our head is not well if our body is weak and debilitated".

BR3. Biopsychosocial conception. Psychological, physical and social dimensions are all included in the conception of disease. However, those dimensions, although interactive, are conceived separately: "The body transmits sensations to the head; the state of mind is negative and that may contribute to cause suffering also to significant others but significant others can help us too ... mental and physical health are inter-related and their relationship with others also helps, contributing to good or bad health".

BR4. Psychophysical parallelism. Psychological and physical dimensions exist, but they never influence each other, they are independent: "Maybe the person is in pain and thinking that he/she is crazy, and sometimes... the head is not well but the body is fine or otherwise. I've felt both ways. There is nothing to do with the head. The head is apart from the body; it has nothing to do with it. I think they are two completely different things; the head has nothing to do with the body".

BR5. Balance between body and mind. Disease is conceived as disequilibrium between body and mind: "Is that balance between mind and body ... if we are pending to one side, the other either compensates or increases the disequilibrium even more. Then it depends on the person ... if he/she will compensate or not and stay even more unbalanced".

After the identification of categories we performed a frequency distribution of responses related to each category and obtained in both spontaneous and after narratives exposure conditions (Table 2). This distribution reveals the most frequent categories and the frequencies for each category before and after the narratives exposure.

As shown in Table 2, in spontaneous responses, the conception of disease as a globally negative and dichotomized state (B2) emerges as the strongest category (e.g., "to be ill is to feel bad", "I am sick if I do not feel well"). Modification of function and/or structure of the body (B1) follow. Not taking profit from life (S1) emerges as the third most frequent response, followed by the psychosomatic relationships. After exposure to the narratives, we can observe that conceptions with a greater degree of differentiation, integration and complexity are more frequent. After N3, the most frequent conceptions of disease introduce the psychological dimension although with a vague and uncertain relation with the physical dimension (BR1). After N4, it is evident a centering on a personal and social dimension of the disease - the disease is conceived as "I feel bad and the others also feel bad" (S3). After exposure to N5, we can see a greater frequency of responses endorsing subjective or personal meanings of the disease (P1).

Based on the data obtained in this study, we proposed a new developmental sequence for significations regarding disease
Table 2. Frequencies of responses related to each disease category.

\begin{tabular}{|c|c|c|c|c|c|}
\hline Categories & Spontaneous & N1/N2 & N3 & N4 & N5 \\
\hline $\mathrm{B} 1$ & 20 & 9 & 5 & 4 & 2 \\
\hline S1 & 18 & 34 & 2 & 12 & 1 \\
\hline B2 & 25 & 11 & 11 & 9 & 1 \\
\hline BR1 & 7 & 6 & 23 & 18 & 19 \\
\hline BR2 & 14 & 2 & 10 & 0 & 2 \\
\hline BR3 & 2 & 1 & 2 & 5 & 0 \\
\hline S2 & 9 & 5 & 1 & 1 & 0 \\
\hline $\mathrm{P} 1$ & 4 & 3 & 2 & 5 & 33 \\
\hline BR4 & 5 & 2 & 11 & 1 & 1 \\
\hline S3 & 2 & 0 & 5 & 27 & 1 \\
\hline B3 & 8 & 0 & 1 & 0 & 0 \\
\hline S4 & 3 & 1 & 0 & 0 & 1 \\
\hline BR5 & 2 & 0 & 1 & 1 & 1 \\
\hline S5 & 7 & 2 & 1 & 1 & 7 \\
\hline Total & 126 & 76 & 75 & 84 & 69 \\
\hline
\end{tabular}

Note: $\mathrm{N} 1 / \mathrm{N} 2, \mathrm{~N} 3, \mathrm{~N} 4$ and $\mathrm{N} 5=$ representative narratives of levels 1/2, 3, 4 and 5, respectively, and included in the Interview Protocol.

processes in adults. For each level, it is indicated the disease category which seems to match each of the different levels.

\section{Developmental sequence of significations regarding disease in adults}

\section{Level 1 - Global bodily sensation; body functionality} (Categories: S2, B2, B3, S5)

This level includes global and undifferentiated perception of bad feelings and/or loss of willing; inability to distinguish causes from symptoms; and perception of the presence of concrete and punctual physical "symptoms" that may be considered as a disease - disease can be defined simply as "lack of health". There is a centering in what the person can or cannot do. Perception of disease can be based on: (a) external signs of disease (e.g., "I cannot do things", "I cannot do my normal life") or (b) global bodily unpleasant/negative sensations (e.g., "I feel bad", "I do not feel well", "I do not have the will to..."). Disease perception may be centered on an unconditional adherence to medical 
significations (e.g., "the doctor says I am sick"). Disease definition is quantitative, global and dichotomized, centered on symptoms and bodily sensations. The person is either healthy or ill.

Level 2 - Bodily centering with somatic differentiation (quantitative and qualitative); psychosomatic parallelism (Categories: B1, BR4, S1)

This level refers to the assessment of a physical condition that does not allow for satisfaction of needs, of impulses and of opportunities of life. Compared to the previous level, body perception is differentiated, including a quantitative and a qualitative evaluation of multiple symptoms or external signs of health. Symptoms perception presents diversified degrees of intensity and frequency. A disease constitutes an obstacle to maximization of profits, wishes, interests and needs, and determines a lack of functional performance, weakening specific abilities to master the environment. There is psychosomatic parallelism: psychological and somatic dimensions exist but they are considered independent. That is, in a disease process, the physical dimension comes first; psychological and physical symptoms may coexist, in detriment of how a person may feel but they do not influence each other. Disease definition is quantitative and qualitative, centered on a physical dimension (physical symptoms), on impulses (uncontrollable) and on material/ physical needs of the person. Emphasis on a body-as-amachine conception.

Level 3 - Sequencing of factors (biological, psychological and social) with biological focus/centering (Categories: S3, BR1 BR2, BR5)

Psychological, biological and social dimensions are described as a sequential mechanism, without interaction or integration. This level comprehends assessment of the presence of physical and psychological (attention problems, memory problems etc.) or relational symptoms that may be presented as more or less differentiated. This assessment is both quantitative and qualitative. The presence of symptoms means that organs and bodily functions are not in good condition. The disease relies on the perception of the bad functioning of the most well known organs (e.g., kidneys, heart, stomach etc.) and of the good evolution of physical (e.g., physical appearance) or psychological (e.g., ability to understand others) attributes mostly connected with relational life. Emphasis is placed on "detrimental effects" of disease over significant others. Disease definition is both quantitative and qualitative, introducing a psychological (e.g., problems of attention, concentration and reasoning) and a social (e.g., relational problems) dimension beyond the physical dimension and personal impulses and needs. However, the relation established between somatic, psychological and/or social processes is still vague and uncertain and it is conceptualized in terms of events sequencing and not in terms of their integration (e.g., "When I am nervous, I am confused, I forget things, I loose appetite, I feel stomach pains. When I am not worried I feel good!", "When I am with those people and I get out with them I become sick right away. They broke me down"). The person is aware that certain "states of mind", "some feelings" or "some relationships" may preclude bodily-function disturbances or make him/her feel even worse. Disease may even be conceived as a loss of bodyspirit equilibrium.

\section{Level 4 - Biopsychosocial interaction (Categories: BR3, P1, S4)}

Assessment of the presence of physical, emotional and cognitive symptoms (e.g., concentration, attention, reasoning) that may be presented as differentiated or interacting one with each other characterizes this level. This assessment is both quantitative and qualitative. The disease relies upon the consideration of the malfunctioning of body structures and/or processes, either in a global way involving bodily systems (e.g., malfunctioning of digestive or cardio-vascular systems) or in a specific way involving specific organs (e.g., malfunctioning of the stomach in terms of gastric secretions). Evolution of the functionality of bodily systems is considered (e.g., increase or maintenance of ability to work, physical/ psychological "shape"). This evaluation is rational and performed by the person and/or the physician. Significations regarding disease process are subjective in nature but can be rationally understood. Perception of disease is also a result of physical and/or emotional excesses evaluated on basis of rational and logical criteria. Disease does not allow the person to comply with his/her duties and obligations (e.g., familial, professional). Disease definition is both quantitative and qualitative and based on an effective interaction between somatic/physical, psychological/emotional and social dimensions. It is, in fact, a biopsychosocial conception of disease. The person is aware that professional, familial stress involves thoughts, emotions or negative feelings that may alter body structures and functions.

\section{Level 5 - Biopsychosocial integration - autonomy/ individuality}

Significations regarding disease processes are centered on the fear of seeing personal autonomy (of thinking and action) diminished; the experience of the disease is based on subjective and idiosyncratic evaluations over the organism which is conceived holistically: psychological, physical and social dimensions are integrated in one sole identity superior to the mere sum of the parts. The perception of disease does not depend necessarily on the presence or absence of symptoms: the perception of symptoms can be followed by an intentional reflection about their meaning, which can be transformed autonomously. That is, the person can adopt conceptions regarding symptoms that are different from other persons (e.g., physician, therapist, friends) or the conventional system (e.g., social rules regarding health; meanings of the health care system), and coordinated at levels of integration more general and abstract (e.g., in perceiving a symptom or corporeal alteration the person can evaluate this as normal in the context of his life and his work, independently of the therapist or other person's meanings). Disease definition is idiosyncratic and based on a dialectical/holistic view of the person and of its environment. 


\section{Percentage of categories by developmental levels}

Table 3 indicates the constellations of developmental categories regarding disease by levels of development and the frequency of responses classified as reflecting each one of the five levels referred to above.

As shown in Table 3, (a) in spontaneous responses regarding disease conceptions there is an incidence on lower and intermediate levels, particularly levels 1,2 and 3; (b) after exposure to narrative $\mathrm{N} 1 / \mathrm{N} 2$, the same pattern of responses is evident. However, a concentration on Level 2 responses is worth of noting; (c) after exposure to narrative N3 and N4,

Table 3. Frequencies of responses related to each disease category grouped by developmental levels.

\section{Levels Categories Spontaneous N1/N2 N3 N4 N5}

\begin{tabular}{|c|c|c|c|c|c|c|}
\hline \multirow[t]{4}{*}{1} & S2 & 9 & 5 & 1 & 1 & 0 \\
\hline & B2 & 25 & 11 & 11 & 9 & 1 \\
\hline & B3 & 8 & 0 & 1 & 0 & 0 \\
\hline & S5 & 7 & 2 & 1 & 1 & 7 \\
\hline Total & & 49 & 18 & 14 & 11 & 8 \\
\hline \multirow[t]{3}{*}{2} & B1 & 15 & 7 & 1 & 1 & 1 \\
\hline & BR4 & 5 & 2 & 11 & 1 & 1 \\
\hline & S1 & 18 & 34 & 2 & 12 & 1 \\
\hline Total & & 38 & 43 & 14 & 14 & 3 \\
\hline \multirow[t]{4}{*}{3} & S3 & 2 & 2 & 5 & 27 & 1 \\
\hline & BR1 & 7 & 6 & 23 & 18 & 19 \\
\hline & BR2 & 14 & 2 & 10 & 0 & 2 \\
\hline & BR5 & 2 & 0 & 1 & 1 & 1 \\
\hline Total & & 25 & 10 & 39 & 46 & 23 \\
\hline \multirow[t]{3}{*}{4} & BR3 & 2 & 1 & 2 & 5 & 0 \\
\hline & $\mathrm{P} 1$ & 4 & 3 & 2 & 5 & 33 \\
\hline & $\mathrm{S} 4$ & 3 & 1 & 0 & 0 & 1 \\
\hline Total & & 9 & 4 & 4 & 10 & 34 \\
\hline
\end{tabular}

Note: N1/N2, N3, N4 and N5 = representative narratives of levels 1/2,3,4 and 5, respectively, and included in the Interview Protocol. we witness an increasing percentage of responses labeled as Level 3; (d) after exposure to N5 there is an increase of responses centered a Level 4 (P1 - disease process integrating subjectivity). In general, it is worthy of note that explicit disease conceptions may be predominantly classified at levels 2 and 3.

\section{Analysis of health significations}

Significations regarding health (i.e., what it means to you to be healthy) could be organized in terms of 12 categories along four dimensions: biological, psychological/emotional, social and biopsychosocial relationships. Following the definition of each category we illustrate it with a typical signification.

\section{Biological dimension (B)}

B1. Functional body. The definition of health is centered on body functionality: "to be healthy it is to have a body that responds adequately to what is expected from it... a body that acts as expected to".

B2. Absence of disease. The definition of health is centered on the inexistence of bodily symptoms, characterized in a global way: "to be healthy it is when the body is not in pain".

B3. Global positive state. Health is defined as a global positive state: "It is when a person feels good with herself/ himself and does whatever is needed to feel that way, taking care of oneself. It is to feel good ... it means that the whole body is well".

\section{Psychological dimension $(P)$}

P1. Subjectivity is integrated in the health process. What health is or not depends in some way on the interpretation people do: "the concept of health varies from one person to another ... for some people, to have some symptoms means not being healthy; for other people, those same symptoms do not mean anything and are not alarming, so they feel healthy ... we can feel a weak pain or some discomfort, but we can still do what we like to do, so it cannot be considered as a disease, it does not affect the person".

\section{Social dimension (S)}

S1. Good physical and psychological functioning for complying with duties. Centering on a good global functioning in the sense that the persons are able to comply with their social responsibilities: "It has to exist that harmony between our body and our mind, which allow us to perform our work and extra-work activities, that allow us to do what we want to do ... and to comply with our duties".

S2. Social functional ability through disease control. Health exists while one is able to play successfully normal social life roles: "If someone is able to control a disease and keep on with a normal social life, he cannot be considered a diseased person". 


\section{Biopsychosocial relationships (BR)}

BR1. Physical and psychological well-being. Health is defined in terms of a global (physical and psychological) well-being: "To be healthy is to feel well physically and psychologically ... it is to feel well, our organism is well, our body, our mind".

BR2. Psychological influences on body functioning. Introduction of a psychological dimension on the definition of health but the relationship between somatic and psychological dimensions is established vaguely and with uncertainty: "The fact that we have no concerns will influence our psychological state, and if we live a calm life it is much more difficult to have diseases associated to those problems; if the "head" is not well the, body, sometimes, also pays the bill".

BR3. Sequencing of biological, psychological and social factors but with a biological centering. Health is defined in terms of prevention and includes biological, psychological and social dimensions: the elements of the different dimensions are described mainly in terms of events sequencing and less in terms of their interaction or integration: "When we are not feeling well psychologically, we become obsessed by the problems that worry us and then we are not able to perform a lot of tasks and social and professional duties, and we do not comply with several routines, even in terms of eating routines. We may eat excessively or less than needed, and the fact that we eat too much or less than needed, we are not eating rationally and our physiological body gets sick automatically. So, we are more vulnerable to diseases".

BR4. Equilibrium (harmony) between physical, psychological and social dimensions. Introduction of a psychological and a social dimension, besides the biological dimension, in the definition of health, but the relationship between somatic, psychological and social processes is established vaguely and uncertainly in terms of an "equilibrium" or "harmony": "To feel well, physically, psychologically and socially, is to be in harmony, it is to be balanced in our daily life".

BR5. Psychosomatic relationships. The psychological and the physical dimensions influence each other but the established relation is characterized in a global and vague way: "To be healthy is to feel well, that means, is functioning as a whole and when this happens it is when we are healthy, ... it is to have total harmony at a psychological and a physical level; any health problem of lesser importance may disturb us as much as if it was a major and severe disease and then it causes some psychological unbalances which are not very healthy. On the other hand, when we are not psychologically well, it reflects also upon the physical level".

BR6. Biopsychosocial parallelism. Physical and psychological dimensions co-exist but they never influence each other. They are considered as independent dimensions: "to be healthy is to be physically well and feeling able to do whatever I want and, on the other hand, to feel psychologically well".

After the identification of health categories we performed a frequency distribution of responses related to each identified categories obtained in both spontaneous and after narratives exposure conditions (Table 4).
Table 4. Frequencies of responses related to each health category.

\begin{tabular}{|c|c|c|c|c|c|}
\hline Categories & Spontaneous & N1/N2 & N3 & N4 & N5 \\
\hline B2 & 17 & 6 & 0 & 0 & 0 \\
\hline $\mathrm{P} 1$ & 3 & 7 & 3 & 2 & 34 \\
\hline BR1 & 20 & 8 & 13 & 3 & 2 \\
\hline BR2 & 0 & 2 & 7 & 2 & 2 \\
\hline BR3 & 0 & 2 & 4 & 3 & 1 \\
\hline S1 & 10 & 7 & 0 & 6 & 1 \\
\hline BR4 & 4 & 2 & 0 & 4 & 4 \\
\hline BR5 & 2 & 2 & 5 & 1 & 1 \\
\hline BR6 & 5 & 2 & 7 & 10 & 2 \\
\hline B1 & 34 & 19 & 7 & 16 & 2 \\
\hline S2 & 0 & 6 & 1 & 2 & 1 \\
\hline B3 & 9 & 2 & 4 & 11 & 1 \\
\hline Total & 104 & 65 & 51 & 60 & 51 \\
\hline
\end{tabular}

Note: N1/N2, N3, N4 and N5 = representative narratives of levels $1 / 2,3,4$ and 5, respectively, and included in the Interview Protocol.

As shown in Table 4, in spontaneous responses the most frequent response refers to health based on the functional ability to perform daily tasks (B1). Performance of daily tasks constitutes the criterion for "good health". Health as physical and psychological well-being (BR1) comes next, followed respectively by health as absence of bodily symptoms (B2), health as having a good physical and psychological functioning for complying with duties (S1), and health as a global positive state (B3). We can say that lay people spontaneously identify health with the functional capacity to work, centering on good bodily functioning or, although in a lesser degree, on physical and psychological well-being. Also worth noting is the conception of health as a global positive state.

After exposure to narratives, the sample's responses are centered on a smaller number of significations regarding health. After exposure to N1/N2, it emerges again a centering on the functional capacity to perform daily tasks. After N3, there is an increasing frequency of responses identifying health with physical and psychological well-being, which adds a psychological element to the physical. After N4, a centering on functional capacity of the body and the conception of health as a positive global state emerges again. After N5 there is a centering on significations that integrate subjectivity or personal meanings on health experiences: health cannot be seen as separated from its personal meanings. 
In general terms, after exposure to narratives, we can note a greater frequency of conceptions that takes into account a psychological dimension, namely the integration of subjectivity in health evaluation.

Below we present the developmental sequence for significations regarding health in adults proposed by Reis (1998). For each level, it is indicated the health category, obtained in this study, which seems to match each of the different levels. The sequence regarding the experience of health evolves from a global and undifferentiated conception based on somatic well being towards a perspective that is integrative and considers the dialectic of the person with their social and physical environment.

\section{Developmental sequence of significations regarding health in adults}

Level 1- Global bodily sensation; body functionality (Categories: B1, B2, B3)

This level includes a global and undifferentiated perception of somatic well-being (e.g. don't feel the body or disagreeable bodily sensations: indisposition, apathy etc.) and/or absence of concrete and discreet physical symptoms (e.g., pain, dizziness, lack of appetite etc.), attributed to illness. Maximization of pleasure based on somatic sensations and impulses. Health perception can be based on (a) external evidence of good health (e.g., I can work or I can go on with my life) and/or (b) pleasant and global somatic sensations (e.g., I feel good). Definition of health is quantitative, global and dichotomized and focused on physical symptoms and bodily sensations.

\section{Level 2 - Bodily centering with somatic differentiation (quantitative and qualitative); psychosomatic parallelism (Categories: BR6)}

This level involves the perception of a physical condition that permits the satisfaction of necessities, impulses and life opportunities, and/or absence of concrete and discreet physical symptoms that can be attributed to an illness. This perception is more differentiated than the perception of the previous level: includes a quantitative and qualitative evaluation of symptoms and external evidence of good health. The perception of symptoms presents diverse grades of intensity and frequency. Health is something that permits the maximization of his/her wishes, interests, needs and functional capacity, and specific skills to control human relations. Definition of health is quantitative and qualitative and focused on (a) physical dimension (physical symptoms); (b) impulses (uncontrollable); and material/ physical needs.

Level 3 - Sequence of factors (biological, psychological and social) with biological focus/centering (Categories: $B R 1, B R 2, B R 3, B R 4, B R 5)$

In this level, it is found the perception (qualitative and quantitative) of (a) absence of physical and/or psychological symptoms (e.g., memory and concentration problems) attributed to illness, and good global functioning of the best known organs (e.g., liver, heart, stomach etc.); (b) good evolution of physical (i.e., physical appearance) or psychological attributes mostly connoted with interpersonal relationship (e.g., capacity to understanding others). Definition of health, both quantitative and qualitative, begins introducing psychological (e.g., memory and reasoning problems physical) and social dimensions (interpersonal problems), but without integration with the biological dimension; the relationship between somatic and psychological and/or social processes is unclear and vague. These three dimensions are depicted in terms of a sequence of events but there is no understanding of the interaction or integration among them.

Level 4 - Biopsychosocial interaction (Categories: P1, S1, S2)

Perception (both quantitative and qualitative) of absence of physical, psychological and emotional symptoms, which can be presented as isolated or as in interaction, is part of this level. Perception of good functioning of physiological structures and functions may be global, in terms of internal corporal systems (e.g., good functioning of cardiovascular and digestive systems), or specific, in terms of organs (e.g., good functioning of stomach with respect to gastric secretion). Also, there is a perception of good evolution of the functionality of corporeal systems (e.g., fulfill the requirements of work, physical and psychological fitness). This is a rational evaluation: meanings of well-being are subjective, but through reason we can understand them. The perception of health results, also, from avoiding engaging in emotional and physical excesses, in accordance with logical and rational criteria, and rational harmonization among physical, psychological and social factors. Definition of health is quantitative and qualitative and with effective interaction of somatic/physical, psychological/emotional and social dimensions. It is a true psychosomatic and biopsychosocial conception.

\section{Level 5 - Biopsychosocial integration; autonomy/individuality}

Health is something that permits personal autonomy (of thought and action). This experience can be interpreted with relativity - it is based on subjective and idiosyncratic evaluations about the organism conceived holistically. The perception of health doesn't depend necessarily on the presence or absence of symptoms: the perception of symptoms can be followed by an intentional reflection about their meaning, which can be transformed autonomously. That is, the person can adopt conceptions regarding symptoms that are different from those of other persons (e.g., physician, therapist, friends) or of the conventional system (e.g., social rules regarding health, meanings of health care system) and coordinated at more general and abstract levels of integration (e.g., in perceiving a symptom or corporeal alteration the person can evaluate this as normal in the context of his life and his work, independently of the therapist or other person's meanings). There is an emphasis on the capacity of development/ transformation of his/her epistemological and ontological 
Table 5. Frequencies of responses related to each health category grouped by developmental levels.

\begin{tabular}{|c|c|c|c|c|c|c|}
\hline Levels & Categories & Spontaneous & N1/N2 & N3 & N4 & N5 \\
\hline \multirow[t]{3}{*}{1} & B1 & 34 & 19 & 7 & 16 & 2 \\
\hline & B3 & 9 & 2 & 4 & 11 & 1 \\
\hline & B2 & 17 & 6 & 0 & 0 & 0 \\
\hline Total & & 60 & 27 & 11 & 27 & 3 \\
\hline 2 & BR6 & 5 & 2 & 7 & 10 & 2 \\
\hline Total & & 5 & 2 & 7 & 10 & 2 \\
\hline \multirow[t]{5}{*}{3} & BR1 & 20 & 8 & 13 & 3 & 2 \\
\hline & BR2 & 0 & 2 & 7 & 2 & 2 \\
\hline & BR3 & 0 & 2 & 4 & 3 & 1 \\
\hline & BR4 & 4 & 2 & 0 & 4 & 4 \\
\hline & BR5 & 2 & 2 & 5 & 1 & 1 \\
\hline Total & & 26 & 16 & 29 & 13 & 10 \\
\hline \multirow[t]{3}{*}{4} & P1 & 3 & 7 & 3 & 2 & 34 \\
\hline & S1 & 10 & 7 & 0 & 6 & 1 \\
\hline & S2 & 0 & 6 & 1 & 2 & 1 \\
\hline Total & & 13 & 20 & 4 & 10 & 36 \\
\hline
\end{tabular}

Note: N1/N2, N3, N4 and N5 = representative narratives of levels 1/2, 3, 4 and 5, respectively, and included in the Interview Protocol.

individuality. Definition of health is idiosyncratic and based on a dialectical/holistic view of the person and of its environment.

\section{Percentage of categories by developmental levels}

Table 5 indicates the constellations of developmental categories regarding health by levels of development and the frequencies of responses classified as reflecting each one of the five levels mentioned above.

It is observed that: (a) in spontaneous responses regarding health significations there is an incidence on lower levels, particularly levels 1 and 2 and 3; (b) after exposure to narrative $\mathrm{N} 1 / \mathrm{N} 2$, a similar pattern of responses is evident; (c) after exposure to narrative N3, we witness a decrease in the percentage of responses labeled as Level 1 and an increase in the percentage of responses labeled as Level 3; (d) after exposure to narrative N4 there is a an increase in the percentage of Level 1 responses. There is also a slight increase in the percentage of Level 4 responses but it is still lower than those obtained after exposure to N1/N2. This may be explained by the fact that most people included in the sample seem to function predominantly at levels 2 and 3 and when exposed to a kind of reasoning typical of Level 4 , strange or contradictory with respect to the familiar one, they tend to function at their usual levels; (e) after exposure to N5, conceptions focuses on health process integrating subjectivity.

\section{Analysis of individual people}

After classifying categories into developmental levels, we analyzed what was the higher level that each person acceded in both spontaneous and after narrative exposure conditions.

As shown in Table 6, after exposure to narratives, and in comparison with spontaneous responses, there are more persons that accede to higher levels. However, not everyone is able to understand or to have access to higher levels, even when he/she is exposed to them. In terms of the disease and health conceptions, only $57 \%$ and $54 \%$ of the participants, respectively, reached Level 4. It was not possible to classify a typical response typical in Level 5. This is in concordance with Kegan (1994) that asserts that only a small percentage of adults ever reach the higher level.

\section{Discussion}

The main purpose of this study was to assess significations regarding health and disease held by adult lay persons and to verify if those significations can be ordered developmentally from least to most mature. The results indicate that adults function at varying cognitive developmental levels regarding health and disease processes. For each health and disease conceptions, it was possible to order the participants responses into a developmental sequence. Each sequence level includes responses characterized by a higher degree of differentiation, integration and complexity than the previous level. The results are congruent with those of other reflexive and empirical studies in the field of health psychology (e.g., Barros, 1992; Fradique, 1993; Joyce-Moniz \& Reis, 1991; Reis, 1992, 1998, 2005, 2007; Travado \& Reis, 2000) and psychotherapy (e.g., Ivey, 1986; Ivey \& Gonçalves, 1988; Joyce-Moniz, 1989; Rigazio-DiGilio \& Ivey, 1990). Interestingly, not all participants were able to understand or

Table 6. Percentages of individuals by developmental level.

\begin{tabular}{lccccc}
\hline $\begin{array}{c}\text { Type of } \\
\text { responses/dimension }\end{array}$ & Level 1 & Level 2 & Level 3 & Level 4 & Level 5 \\
\hline Spontaneous/disease & 22 & 40 & 28 & 9 & - \\
After exposure/disease & - & 7 & 36 & 57 & - \\
Spontaneous/health & 19 & 40 & 34 & 33 & 54 \\
After exposure/health & - & 13 & - & - \\
\hline
\end{tabular}


have access to higher developmental levels even when they were exposed to them, a result that is similar with those of other studies (e.g., Kegan, 1994; King \& Kitchener, 1994; Reis, 1992).

In fact, only $57 \%$ of the participants with the disease conception and $54 \%$ of the participants with the health conception reached Level 4. Also, it was not possible to classify a typical response of the higher level even when the participants were exposed to typical narratives of this level. One possible explanation for this result could be that the language used in each of the narratives was too sophisticated for some participants due to their low socioeducational level and/or poor reading skills. This could have caused difficulties to reflect about written narratives. In a future study, an alternative method to overcome this limitation would be to have the participants exposed to a videotape depicting actors dramatizing the typical narratives of each developmental level. The exposure to another person expressing significations regarding health and disease processes in a way that is less abstract, more related to real-life situations, may facilitate the understanding of the narrative meanings.

The data also points out that after exposure to narratives there were more participants that reached higher levels. This result suggests that when we intend to assess another persons' significations through simple questioning, without exposing them to a contradictory or different way of thinking, we are not able to evaluate the maximum potential for which that person is able to function.

The developmental perspective presented in this study has two main implications for clinical and educational processes. First, intervention methodologies in clinical and health psychology can be differentiated according to signification levels (Joyce-Moniz \& Reis, 1991). Therefore, it will be necessary to harmonize clinical and educational strategies with the person's cognitive-developmental levels (Joyce-Moniz \& Reis, 1991; Reis, 2007). Otherwise, our clients may be exposed to rationales and intervention strategies that they may feel as strange and incompatible with their socio-cognitive competencies. It seems that it would be useful and of greater efficacy to plan the use of clinical strategies as well as educational goals according to the competences allowed by different levels of signification. Even though some therapists and educators tend to focus on varying cognitive levels, clinical and educational procedures are implemented greatly on basis of clinical "intuition". However, from a developmental perspective, clinical methodologies should be planned according to predictable "developmental movements" that are, in turn, ordered through socio-cognitive developmental sequences. Second, sometimes it is important to facilitate client explorations, that is, developmental movements may be provoked by exposing the client to significations that do not harmonize with their own or are even contradictory to them (King \& Kitchener, 1994; Rigazio-DiGilio \& Ivey, 1990). Thus, a person should not be exposed only to significations expressing equal or lower levels than his/her own. Typical examples of higher developmental levels should be presented. This would offer the opportunity for the person to evolve to a more highly differentiated and complexly organized level of meaning- making (Barros, 1992; Fradique, 1993; Ivey \& Gonçalves, 1988; Reis, 1992). Alternatively, the client would have the choice to keep functioning at the same level but doing it in an improved and structured manner.

In conclusion, the developmental approach based on a socio-cognitive framework offers the clinician and the researcher a useful framework for making decisions about clinical and educational procedures related to health and disease processes.

\section{References}

Barros, L. (1992). Intervenção desenvolvimentista com pais de bebés em risco. Doctoral Dissertation, Universidade de Lisboa, Lisboa.

Basseches, M. (1984). Dialectical thinking and adult development. New Jersey: Ablex.

Bibace, R., \& Walsh, M. (1979). Developmental stages in children's conceptions of illness. In G. C. Stone, F. Cohen \& N. E. Adler (Eds.), Health psychology (pp. 285-301). San Francisco: Jossey-Bass.

Bibace, R., Schmidt, L., \& Walsh, M. (1994). Children's perceptions of illness. In G. Penny, P. Bennett \& M. Herbert (Eds.), Health psychology: A lifespan perspective (pp. 13-30). London: Harwood Academic.

Broughton, J. (1980). Genetic metaphysics: The developmental psychology of mind-body concepts. In R. Rieber (Ed.), Body and mind (pp. 177-221). New York: Academic Press.

Burbach, D. J., \& Peterson, L. (1986). Children's concepts of physical illness: A review and critique of the cognitivedevelopmental literature. Health Psychology, 5, 307-325.

Cameron, L. D., \& Leventhal, H. (2003). The self-regulation of health and illness behaviour. London: Routledge.

Cohen, F., \& R. Lazarus (1979). Coping with the stresses of illness. In G. C. Stone, F. Cohen \& N. E. Adler (Eds.), Health psychology (pp. 217-254). San Francisco: Jossey-Bass.

Coyne, J., \& Holroyd, K. (1982). Stress, coping and illness: A transactional perspective. In T. Millon, C. Green \& R. Meagher (Eds.), Handbook of clinical health psychology (pp. 103-127). New York: Plenum.

Fradique, F. (1993). Programa desenvolvimentista para a prevenção da depressão pós-parto. Doctoral Dissertation, Universidade de Lisboa, Lisboa.

Ivey, A. E. (1986). Developmental therapy: Theory into practice. San Francisco: Jossey Bass.

Ivey, A. E., \& Gonçalves, O. F. (1988) Developmental therapy: Integrating developmental processes into the clinical practice. Journal of Counseling and Development, 66, 406-413.

Joyce-Moniz, L. (1989) Structures, dialectics, and regulation in applied constructivism: From developmental psychopathology to individual drama therapy. In O. Gonçalves (Ed.), Advances in the cognitive therapies: The constructive-developmental approach (pp. 45-89). Porto: Apport.

Joyce-Moniz, L. (1993). Psicopatologia do desenvolvimento do adolescente e do adulto Lisboa: McGraw-Hill.

Joyce-Moniz, L., \& Reis, J. (1991). Desenvolvimento e dialéctica de significações de doença e confronto em Psicologia da Saúde. Psychologica, 6, 105-127. 
Kegan, R. (1994). In over our heads. The mental demands of modern life. Cambridge: Harvard University.

King, P., \& Kitchener, K. (1994). Developing reflective judgment. San Francisco: Jossey Bass.

Kohlberg, L. (1969). Stage and sequence: The cognitivedevelopmental approach to socialization. In D. Goslin (Ed.), Handbook of socialization theory and research (pp. 347-480). Chicago: Rand McNally.

Leventhal, H., Nerenz, D., \& Steele, D. (1984). Illness representations and coping with health threats. In A. Baum, S. Taylor \& J. Singer (Eds.), Handbook of clinical health psychology (pp 219-252). New York: Plenum Press.

Loevinger, J. (1966). The meaning and measurement of ego development. American Psychologist, 21, 195-206.

Perrin, E., \& Gerrity, P. (1981). There's a demon in your belly: Children's understanding of illness. Pediatrics, 67, 841849.

Piaget, J. (1926). La représentation du monde chez l'énfant. Paris: PUF.

Piaget, J. (1970). Genetic epistemology. New York: Columbia University.

Reis, J. C. (1992). Metodologia construtivista e desenvolvimentista para prevenção de reacções emocionais excessivas em pacientes de cirurgia cardiaca. Doctoral Dissertation, Universidade de Lisboa, Lisboa.

Reis, J. C. (1994). Importância do método clínico ou de exploração crítica no estudo da personalidade. Intervenção Social, 10, 9-23.

Reis. J. C. (1998). O Sorriso de Hipócrates: a integração biopsicossocial dos processos de saúde e doença. Lisboa: Vega.

Reis, J. C. (2005). O que é a saúde? Significações pessoais, modelos científicos e educação para a saúde. Lisboa: Vega.

Reis, J. C. (2007). Contribuições da psicologia para os processos preventivos e de promoção da saúde. In J. C. Teixeira (Ed.), Psicologia da saúde: contextos e áreas de intervenção (pp. 101-128). Climepsi Editores: Lisboa
Reis, J. C., \& Fradique, F. (2000). Socio-cognitive development of subjective representations about health and disease: Implications to health education (Report: Praxis/PCSH/C/PSI/89/96). Lisboa: Fundação para a Ciência e Tecnologia.

Reis, J. C., \& Fradique, F. (2002). Desenvolvimento sociocognitivo de significações leigas em adultos: causas e prevenção das doenças. Análise Psicológica, 1, 5-26.

Rigazio-DiGilio, A., \& Ivey, A. E. (1990). Developmental therapy and depressive disorders: Measuring cognitive levels through patient natural language. Professional Psychology: Research and Practice, 21, 470-475.

Rosenstock, I. M. (1966). Why people use health services. Milbank Memorial Fund Quarterly, 44, 94-127.

Selman, R. (1980). The growth of interpersonal understanding. New York: Academic Press.

Skelton, J., \& Croyle, R. (1991). Mental representations in health and illness. New York: Springer-Verlag.

Travado, L., \& Reis, J. (2000) What do they think about their illness? Breast cancer client's conceptions about their illness and recovery [Abstract]. Psycho-Oncology, 9, Sep-Oct.

Turk, D., \& Meichenbaum, D. (1991). Adherence to self-care regimens. The patient's perspective. In J. J. Sweet, R. H. Rozensky \& S. M. Tovian (Eds.), Handbook of clinical psychology in medical settings (pp. 249-266). New York: Plenum.
Recebido em 17.01.08

Primeira decisão editorial em 23.10.08

Versão final em 10.09.10

Aceito em 10.09.10 